\title{
Historical Transformation of Gender Identity
}

\author{
Theoretical Explications in Postmodernism Context
}

\author{
Liubov Bronzino \\ Department of Sociology \\ Faculty of Humanities and Social Sciences \\ Peoples' Friendship University of Russia \\ Moscow, Russia \\ E-mail: lbronzino@gmail.com
}

\author{
Elena Kurmeleva \\ Department of Social Philosophy \\ Faculty of Humanities and Social Sciences \\ Peoples' Friendship University of Russia \\ Moscow, Russia \\ E-mail: kurmelena@gmail.com
}

\begin{abstract}
Gender inequality is still an important and frequently discussed problem both in everyday life and science. Its source and genesis were clearly identified by different variation of feminist theory, but the solution, which was able to change all sides of gender relation, wasn't find. The classical feminism was involved into making decisions with regard to political, legal and economic problems of the females, but could not change 'man's mind'. Postmodern feminists as a phenomenon do not exist for mass consciousness and doesn't influences everyday life of modern Russian society.
\end{abstract}

Keywords-gender identity; classic-liberal feminism; postmodern feminism; Self; identification practice; gender stereotypes

\section{INTRODUCTION: THE TRADITIONAL FEMALE IDENTITY}

The conceived by men the ideal of a woman appeared to be not too bad: it incorporated the idea on the essential difference between a male and a female, i.e. the gap every male could bridge only by undertaking the earnest efforts. As a result, the female image was evolving as something mysterious and unattainable - each of its facets had its own meaning, the appealing feature, and relevant either for a male or the created by him social environment.

The theoretical development of the approach was long and impacted by social practice reflecting its intrinsic inconsistency. On the one hand, the unattainability as an integral part of a female image assumed certain ephemerality and sublimity. On the other hand, when it comes to the image of a gorgeous virgin who waits for the sole and unique love for ages, or to the image of a mother who is ready to give all her life for her children, a woman was essentially ambivalent: girlhood became a fairy tale with the happy end only thanks to marriage, and the outcome clearly indicates that the parties had originally sticky fingers in their intentions; motherhood is gained by the blood and pain from the time of the original sin (female, as it is known), except for one case of Immaculate Conception. Physiological detraction of a female has become an integral part of everyday life, influenced by cultural and routine practice with the sacral notions transforming into the profane one. The lack of reflection on men's immorality is most likely the result of replacement of morality, which they never make pretense of, by rationality as the way of making their primitive behavior both socially acceptable and important as long as it is reasonably limited by regulatory requirements.

The understanding of the women's status was also ambivalent: until the certain time a woman was not considered a specific research object. It has a simple explanation: any reflection was the privilege of men, who view the current state of affairs as natural, and therefore there were no grounds for the advent of particular knowledge. The ideal of a woman continued its path in literal and historical myths while taking no care on its mismatch to the reality, demonstrating its resistant meaning and social and erotic perversions of the legends embodied in stereotypes. As a result, women's problems arose thanks to the women themselves. Their interpretation was feminist a priori, in other words, it was negative and opposition-oriented, i.e. directed against their social status, cultural attitudes, political and economic differences, which were interpreted in terms of discrimination.

A woman was identified in accordance with the ideal that underwent some changes, however the everyday practice never destroyed it. The latter combined the worship with beating his wife on Sundays immediately after a husband returned from the church, a pub or brothel bawdy house. The usual identification practice for a woman was the happy marriage, otherwise she risked to find herself in the latter of the above-mentioned destinations.

The first advantage of the female ideal was its absoluteness: marriage, housework, and the birth of children were its mandatory attributes representing a full list of the identification practices. The today's nostalgia for a lost ideal is to a greater extent the longing for stability: a limited selection of roles left neither freedom, nor responsibility, most importantly, it clearly outlined the potential life strategies: being a woman is meant to being a good wife or good mother, and their upbringing was the primary intent of girl's socialization. The divergence from the regulatory specified "career" was considered a deviation, the wider window of opportunities implied a social label and isolation.

The Past Strict Identification Practices Are Still Alive Nowadays. A woman has far more opportunities, in addition 
to all the complexities of identification that are related to the transformation of moral values, which defined "liquid modernity", she has to match the ideal yet playing the assigned to men roles in her everyday practices. The most striking demonstration of an ever-living source and stability of gender stereotypes is the advertising that represents actual legitimate discourse of a particular society. As a rule, a woman is shown in the following way: either as part of kitchen and bedroom interiors or with countless washing powders and utensil cleaners; as a seductress flirting with a man, who is sexual hunter [1]. The result was bound to be a huge amount of gender studies by women that still irritate almost all the male representatives of the scientific community as well as the ongoing fight with patriarchate that it is impossible to overcome with political declarations and strict legal regulations prohibiting the discrimination. It happens not only because gender stereotypes are supported by men unwilling to take a back seat but also because the latter corresponds to the still dominant social identification of the majority of women. The problem exists not in politics but in human minds. It is the main task for feminists starting from the first suffragettes.

\section{UPRISING OF THE "SECOND GENDER"}

The final finding was not made at once and all of sudden: it took women much time to understand that men should not be always blamed for all. Everything had its roots in politics - having declared the class equality, sooner or later men had to conclude that social injustice is embodied in gender discrimination. A brief historical summary makes it clear that many suffragettes and feminists, who are thought to be "insolvent", struggled not in vain: woman suffrage has been internationally legalized only in 1948 and the legislation of many European countries prohibited it for a long time. However, as the problems have persisted for over a half of century, formal consolidation of the equal rights was not the only reason - egalitarianism is essentially contradictory process. It appears to originate from the patriarchal social organization, as well as from the perception of a woman as Other, a "second-grade gender". The latter is reflected in the basic philosophical and social dichotomies: rational irrational, good - evil, active - passive, true - false, etc. In this case, the reality seems to be unimportant, but what is essential is the symbolic labeling of a female as being secondary (a synonym to absence or drawback). The gender identification by its definition turns out to be an incomplete process due to the fact that it is carried out via a full-fledged male, who is identifying himself. Sigmund Freud provided the scientific rationale, thus initiating the discussion about the complexity of women's identification and as a result, he became a culprit from the females' standpoint: 'For the feminist theorists Freud stands behind the fact that he considered women only as a form of men, as an individual point of view. Women were neither legislators nor lawmakers in this society, they therefore must be essentially quiet and passive. They are the-lowest-rank beings that are able to reach the outside world only through the man's strength that is the scepter/phallus' [2. P. 81].
Freud uncovered the irrational and became the target of feminist's criticism due to his intention to determine the specifics of women based on the idea of solid identification practices within the patriarchal system, whereas feminists recognized the deep-rooted women's desires and grasped the reason of the infeasibility. Women feel themselves belittled because the requirements that are imposed on them by society really diminish them. Deep inside they want to become full-fledged individuals, free society agents, who possess their future and the whole world [3]. Simone de Beauvoir explained to the women why they are not deserved to be "a second-grade gender", and legitimized intellectually and ideologically the certain way of life by her behavior.

\section{THE LURE OF LIQUID MODERNITY AND THE SEDUCTION OF IDENTITY}

It would seem impossible to go beyond the classical feminism that squared accounts even with men in all spheres - from politics to sexuality - but the advent of postmodernism broke the perfect scheme. There society emerged, in which sustainability and stability seem unreachable goals, while social norms are too volatile and changeable that identification of any human being, whether a male or a female, turns into an uninterrupted process, which equals to lifetime. The number of answers to the question "Who am I?" that have to put an end to self-identification is too numerous. Once a mindset was internalized, a new identification goal was already offered to an individual. $\mathrm{He} / \mathrm{she}$ adjusts to the calls of time and considers each of his/her miscellaneous and short-lived masks as significant. The identity seems to be solid only when looked from the outside. Whatever solidness it had, when looking from within, from the point of view of the individual biographical experience, it seems to be fragile, vulnerable, and constantly torn up by internal forces that dismantle its fluctuation with external streams threatening tear to ribbons and throw away any perceived form. Experienced, tested identity can keep its integrity only with help of fantasy and, perhaps, dreams [4]. Identity has a limited lifespan, yet it can never be completely formed, staying permanently imperfect and incomplete [4].

Zygmunt Bauman points to the outer solidness of identity; Jean Baudrillard even denies the sustainability of its form the body that must transform along with the fashion, overcome the ageing thanks to novelties in medicine and demonstrate success by replacing defective components. Baudrillard was not satisfied with the feminist interpretation of women's and men's identity (even in postmodern feminism) as it keeps the representations of femininity and masculinity as equal, albeit different concepts. "The feminine is something that goes beyond the confrontation and, consequently, eliminates sexual identity in a certain sense" [5]. Women still cannot gain their complete identity, although the reason is that the identity (either male or female) does not exist. There is only illusory freedom to choose an identification of either of the sexes (even "the third one") and try to grasp it through continuously changing "eluding" signs that are impossible to secure or to reflect, creating a sensebearing self-image. 


\section{TeXt Deconstruction OF Gender}

Some time passed and a new approach emerged, however a woman is found again in the role of a seducer and viewed as an individual case of some universal reality - the unforeseen contingency is unexpected and unacceptable for feminists. Let us make some chronological disorder for clarifying the theoretical context: as a result of mix of Freud's ideas and postmodernism, there emerged the concept of Jacques Lacan, also known as "French Freud" thanks to the tag introduced by Michel Foucault. He became the progenitor of the French postmodern feminism. The way included the move away from 'gender identity to speech and from the bottom to the morality' [6].

French postmodernist and feminist concept proposes the idea of women's self-identification outside the discourse of the patriarchal system, the practice of forming identity equals to the practice of writing [7]. We can replace the slogan "The woman must be self-aware" to the set of instructions about how to reach this self-awareness by means of postmodernists' idea about the power of discourse. The woman's self-identification has been made not by herself, but by men, more precisely, by a social mechanism created by men that was focused on the suppression of female identity. It means that a woman had no possibility to realize herself as an integral autonomous personality possessing independency in making decisions about her own actions and views about herself - she was always forced to comprehend herself as part of male identity. In other words, a typical woman as an embodiment of femininity and a set of standards, which are supposed to be the identification processes, did not exist at all. These standards should occur when a bulk of women's texts describing individual experience is created. Afterwards female identity will turn into a clear construct created by the women themselves and therefore authentic.

The construction of symbolic, social, and role-playing identity is feasible through the writing but it should be based on the body that is not treated as a source of the sin anymore, as it was created for enjoyment (jouissance). A strict social norm was established for women, according to which the female sexuality should be neglected. That is why a woman feels guilty when her sexuality yet appears. It is the standard social sanction, a testimony of woman's "abnormality" that is marked in men's world as deviation. In such societies shame becomes the highest hazard or absolute evil. The women as passive objects are nevertheless perceived as tricky "witching force", the people in power must defend against [6].

Men seek to organize the society that they consider reasonable and worship Logos. For men this approach guarantees the social, economic, and sexual power. Because of this social order at the moment it is difficult to imagine some ways of identification outside it. Revolutions and rioting that seemed to be the best way to fight for women rights and should have led to the New Woman, failed for the reason that they were a part of men's approach. It would be a struggle rather "against" men than "for" women; so the consciousness of a woman herself has not changed even if she gained her political and economic rights. Thus, for identification transformations the wrong method was chosen: we need to "write" a woman. The writing is a way of building the symbolic systems that define a social order as was indicated by structuralism and poststructuralism. Consequently, to create a woman's writing means to build new social bases, within which woman's identification will be formed for a woman in her individual capacity, not a woman as a shadow or 'a servant to an aggressive man' [7].

The problem is obvious - it is supposed to create a symbolic way of the formation and interpretation of reality that has not existed before. In addition, a woman is diverse in her performances so it is very difficult to outline the joint scheme that would be suitable for any woman. Moreover, there is no special code in the current culture because all codes we have are brought by men and directed on the formation of identification mechanisms that support the existing social order. However, if it is possible to cope with this task, the orientation to a private writing can become the source of knowledge about society, destroying "men's society", "men's history", and "men's science".

Despite all vagueness of identification mechanisms and mainly its orientation, we can nevertheless distinguish two basic points that fix the proposed by postmodernist feminism pattern of identity. Firstly, a woman still must realize herself as a mother but without any orientation on by men prescribed role, according to which the woman is only one of the family system element. Gender roles and traditional conception of mother as a successor of the kin are locked in her, when "a born baby brings into life father" [7]. Woman must reject this compulsion and realize herself as a mother because of her desire to give birth to a baby.

Secondly, a woman was born for love, however it does not mean any shortage or victim. A woman always feels herself loving and giving love but it was interpreted by men as a gift, which requires pay-offs because, according to men's reasoning, it is impossible to save the integrity giving a part of oneself to others. That is why a man always treats a woman in terms of exchange rather than gift. He thinks in economic categories that bode well to the reasoning within the patriarchate regime. On the contrary, a woman is capable of saving her "Self" despite losses and sacrifices because her integrity discounts diversity, her "chaotic space" integrates "the clique of referents". The economic indicators, based on which a man pursues his identification, are not of major importance for a woman, as she improves emotionally and psychologically and does not need any external manifestations to confirm her identification confirmation, 'unlike a man, who is pegged to his name and title'[7].

We do not know whether many women followed the advice to write their selves and identify themselves through the letter, but for the feminist-oriented readings it seems to be a guideline. The process was accompanied by the increased interest to Lacan that determined the nature of subjectivity - it became deconstructive. Kristeva's woman is a result of the symbolic order distortion and disruption of the representation order. She carries the distortion over to the 
process of writing/speaking that is aimed at developing a deconstructed subject of the utterance [6].

While feminism has recently reached Russia, the influence of Kristeva's and Lacan's thoughts came immediately in full swing. For women the best way to write their selves is seemed to be writing about women. It turned out that the usual everyday reality of the modern Russian society (overwhelmed with paradoxes of the mixed Soviet and modern Western symbols) for the analysis in the spirit of Lacan is not worse compared to the classical Western one. Olga Kirillova attended the seminars about Lacan much later, and now interprets many female images of mass post-soviet culture in line with Lacan's theory. There are no direct orientation to the Soviet cultural space or feminism as theoretical or ideological canvas of researcher's preferences in the book [8] (however, there are a lot of his ideas again), but both can be read in the context that is oversaturated with specific connotations, which are possible only in specific cultural environment. We cannot guarantee that such an interpretation will be appealing to the author, however she seems to write her self as Helen Cixous and Julia Kristeva advocated.

In the process of deconstructing women's in images and symbols that fundamentally differ in form, substance, and even geography, Kirillova finds the basic elements of construction of women's subjectivity and poles of virginmother's binary opposition. This includes the mother's "super-ego", girlhood, and innocence. These images are unified by the pronounced connection with the historical context of the Soviet period, which had an impact on the author's socialization. They carry the average post-soviet individual archetypes, but the author disregards their pronounced gender dimension while demonstrating them in the text.

A post-Soviet woman, filled with Western intellectual spirit, is not an average woman anymore but enlightened with Western-style, feels herself free and able to grasp the "floating signifiers" of mass stereotypes in a slightly cynical and relaxed manner. Behind a bulk of Lacan's and the other psychoanalytic and postmodern terms an incurable romantic stands, who is rather special feminist, neither fights with men, nor defends herself by all means. Instead, she is watching and waiting for the moment when she can finally cease to be a feminist and a strong woman while following her beloved man as the God rather than Lacan wills. The author restores (in the sense of Cixous) her own style of speaking, builds the woman's discourse through the set of standardized mass culture images and writes her self, deconstructing the images and trying to restore the lost subjectivity, turning into 'the projection that Lacan aimed to produce' [8. P. 144]. The book by Kirillova in this sense appears to be a curious and crucial precedent.

\section{CONCLUSION}

Even the essay-style thinking requires some conclusions, in this case regarding how gender/women's identity evolves today. However, it seems that failure to find the only answer to the question of identity leads to the multiple solutions, among which it is hard to search not even the right but just the mainstream or acceptable one.

There was the system of identification practices that were necessary to maintain the existence of a particular type of society in the understanding of gender identity (later marked as patriarchal). The classical feminism was involved into making decisions with regard to political, legal and economic problems of the females, and in this case we cannot but acknowledge its merits. At the same time, the image of a modern woman has not always transformed for the better under its influence: feminists spoiled the reputation both for themselves and for "self-made women", who are usually identified with them. The latter did not gain attractive features in the conservative mass consciousness: under a business suit, they hid their difficult choice sacrificing private life for career; it is designed to hide bad nature, moral ambivalence, and sexual immorality.

Postmodern feminists as a phenomenon do not exist for mass consciousness. Moreover, they look exotic even for sophisticated scientific consciousness: they write and speak in an abstract and open manner, they are wordy and not used to express themselves clearly. Even those, who managed to understand what they really wanted to say, cannot be sure that the suggested way of identifying is really feasible and not a literature fiction, "ego-discourse", required for an author, who is forever lost in the wilds of means to write her self.

It is even harder to believe in the Russian version of postfeminism - specifically Soviet feminine ideals are still alive in memory. Looking at an unfeminine face of a Soviet woman, one can turns back upon feminism forever: it would be better to raise again gender inequality, which takes apart at least male and female spheres of activity. Nowadays there are unfortunately only a few that can afford themselves something like this. Intellectually oriented women are forced to follow the experience of fascinating with beauty discourse game of the Western postmodern feminists. Anyway, even if a woman finds herself in social and intellectual rise in Russia, she would prefer not to tell anyone about it.

\section{REFERENCES}

[1] Iu. P. Lezhnina, "The Transformation of Gender Roles in Today's Russia," Sociological Research, 2014, vol. 53, issue 5, Taylor\&Francis Online.

[2] R. Lamont, "The Reverse Side of a Portrait: The Dora of Freud and Cixous", in Feminine Focus. The New Women Playwrights, New York, Oxford: Oxford University Press, 1989, pp. 70-93.

[3] S. de Beauvoir, The Second Sex. New York: Vintage Books, a division of Random House, Inc., 2010.

[4] Z. Bauman, Liquid Modernity. Polity Press, 2000.

[5] J. Baudrillard, Mots de passe. D'un fragment à l'autre. Paris: Éditions Galilée, 2000.

[6] J. Kristeva, Powers of Horror: An Essay on Abjection. New York: Columbia university press, 1982.

[7] H. Cixous, The Laugh of Medusa. Oxford University Press, 2006.

[8] O. Kirillova, The Hook of the Cold Moon: The Reconstruction of Sensibility Models, St. Petersburg: Aleteya, 2010. 